\title{
Preparation of the Rutin-SBA-16 Drug Delivery System
}

\author{
Juliana Camila Fischer Karnopp', Teófilo Fernando Mazon Cardoso², Daniel Araujo Gonçalves³, \\ Aline Regina Hellman Carollo², Gustavo Rocha de Castro4, Adriana Pereira Duarte1, \\ Marco Antonio Utrera Martines ${ }^{{ }^{*}}$
}

${ }^{1}$ Institute of Chemistry, Federal University of Mato Grosso do Sul, Cidade Universitária, Campo Grande, MS, Brazil

${ }^{2}$ Faculty of Pharmaceutical Sciences, Food and Nutrition, Federal University of Mato Grosso do Sul, Cidade Universitária,

Campo Grande, MS, Brazil

${ }^{3}$ Department of Chemistry, Minas Gerais State University, Ituiutaba, MG, Brazil

${ }^{4}$ Institute of Biosciences, Sao Paulo State University, Botucatu, SP, Brazil

Email: *marco.martines@ufms.br

How to cite this paper: Karnopp, J.C.F., Cardoso, T.F.M., Gonçalves, D.A., Carollo, A.R.H., de Castro, G.R., Duarte, A.P. and Martines, M.A.U. (2020) Preparation of the Rutin-SBA-16 Drug Delivery System. Journal of Biomaterials and Nanobiotechnology, 11, 1-13.

https://doi.org/10.4236/jbnb.2020.111001

Received: October 7, 2019

Accepted: November 8, 2019

Published: November 11, 2019

Copyright $\odot 2020$ by author(s) and Scientific Research Publishing Inc. This work is licensed under the Creative Commons Attribution International License (CC BY 4.0).

http://creativecommons.org/licenses/by/4.0/

\begin{abstract}
This study sets out a scheme for a controlled release delivery system using SBA-16 as a carrier matrix and Rutin as a drug (Rutin-SBA-16). Physicochemical characterizations were performed to confirm the structure of the SBA-16 for post-synthesis by scanning electron microscopy (SEM), Transmission Electron Microscopy (TEM) and X-ray Diffraction (XRD). The presence of Rutin-SBA-16 was confirmed by Fourier-transform infrared spectroscopy (FTIR) and Nitrogen adsorption-desorption isotherms at $77 \mathrm{~K}$. The dissolution kinetics was evaluated by the Zero Order, First Order and Higuchi models, and Rutin quantification was carried out by High Performance Liquid Chromatography (HPLC). The best impregnation time, which was 8 hours, adsorbing $284 \mu \mathrm{g}$ Rutin per mg of silica, and the maximum degree of dissolution occurred in a period of $20-25 \mathrm{~h}$. The release kinetics of the Rutin was called Higuchi, and showed high linearity, with a correlation coefficient $\left(\mathrm{R}^{2}\right)$ of 0.999 compared with 0.905 and 0.980 of the zero order and first order models respectively. The study shows the benefits of Rutin-SBA-16 as a drug delivery system.
\end{abstract}

\section{Keywords}

Rutin, Controlled Release Systems, Kinetic Study, Mesoporous Silica, Flavonoid

\section{Introduction}

When administered in oral dosage forms, for example in tablets, drug absorption 
depends on the ability of the drug to be released from the formulation and to dissolve under physiological conditions, as well as on its permeability along the gastrointestinal tract [1]. This ability of the drug to be released (i.e. its availability) is assessed through dissolution studies, which allow the release profile of a drug to be inferred from its parent pharmaceutical form by conducting an analysis at predetermined times. Through the obtained data, the key parameters for the availability of the active principle can be estimated, and thus allow a qualitative and quantitative evaluation of some of the formulations [2].

When a drug is administered, only a part of the dose reaches the desired goal, and a larger amount is spread to other tissues before reaching the target, this means your metabolism or excretory function can be affected before the drug reaches the site of action [3]. This has become a serious problem in the treatment of various diseases such as cancer and leishmaniasis, in which the treatment itself is painful, owing to the serious adverse effects that can be attributed to the lack of specificity and uneven distribution of the drug [4] [5].

One strategy that can solve this type of problem may be the use of a drug delivery system (DDS), that is based on an array of drugs that is capable of conveying a modified-release dosage to the target tissue and cells [6]. This involves employing a particulate carrier matrix system, in which the drug can either be scattered or retained in the matrix, encapsulated in the core or adsorbed on the surface. The advantages of DDS are as follows 1) it keeps a constant level of the drug in the body; 2) it reduces the risk of a dose either being too high or too low; 3) it reduces the number of times required for administration; 4) it provides a better use of active agents and other factors. All of this add to the comfort of the patients and improve the effectiveness of the treatment [7].

The array used in the DDS must comply with a number of requirements before it can be considered to be efficient. It must be biocompatible, able to encapsulate or incorporate a high volume of drug dose, allow premature drug release, have the ability to get to a particular tissue and enable the drug to be released in a controlled manner [8]. Several arrays are currently being studied which have a potential use in DDS, such as polymeric micelles, dendrimer, chitosan nanoparticles, mucoadhesive nanoparticles and mesoporous materials, each with their own particular features and specificity [7] [9].

It should be noted that the mesoporous materials have gained prominence since they can be used as carrier matrices [10]. The organized structure of the mesoporous materials makes them useful for several applications, including the ability to serve as a matrix in the drug delivery system (DDS). Among the mesoporous materials, silica has become a good candidate because it has excellent properties such as an orderly mesoporous structure, adjustable pore diameters and volumes, a large surface area and the presence of silanol groups on the pore surface, atoxicity, and biocompatibility. As well as this, its surface can be modified to the controlled process of adsorption and the kinetics of drug release [8] [11].

Among the support materials studied in catalytic reactions, mesoporous sili- 
cas such as MCM ("Mobil Composition of Matter") and SBA ("Santa Barbara Amorphous") silicates have been shown to be good supports because of their large surface area, (i.e. $\sim 1000 \mathrm{~m}^{2} \cdot \mathrm{g}^{-1}$ ), adjustable pore sizes (i.e. $2.0-10.0 \mathrm{~nm}$ ) and uniform pore size distribution [12] [13]. However, the SBA-16 is regarded as one of the most valuable mesostructures, since it has a cubic 3D arrangement of mesopores in the form of a cage corresponding to a spatial area of $\operatorname{Im} 3 \mathrm{~m}$, which have high thermal stability and are generally synthesized in a low $\mathrm{pH}$ solution [14] [15]. For this reason, the organized structure of the SBA-16 materials provides them with useful features for several applications, including the matrix in the drug delivery systems.

This study sets out a scheme for a controlled release system using SBA-16 as a carrier matrix and Rutin as drug. Rutin $\left(\mathrm{C}_{27} \mathrm{H}_{30} \mathrm{O}_{16}\right.$, molecular mass 610.52 $\left.\mathrm{g} \cdot \mathrm{mol}^{-1}\right)$ (Figure 1)) is a flavonoid extracted from plants, such as Fava d'anta (Dimorphandra mollis Benth), a Brazilian species of the Brazilian Cerrado (the vast tropical savanna region in Brazil), of the legume family (Leguminosae) [16]. The Rutin is known for its multiple pharmacological properties, such as antitumor, antioxidant, anti-inflammatory, anti-depressant and antiviral activity, and cardioprotective mechanisms. It also has a beneficial effect by 1) reducing the concentration of low density cholesterol; 2) taking action to strengthen the structure of the blood vessel wall layers by making the veins more resistant and 3) overcoming problems related to poor blood circulation [17]. Thus, the combination of the essential properties of mesoporous silica with natural products has aroused interest in studies concerned with the spread of these molecules from a controlled release system.

\section{Materials and Methods}

\subsection{Reagents and Solvents}

Cetrimonium bromide-CTAB (BioXtra, $\geq 99 \%$, Sigma), TetraethoxysilaneTEOS (Reagent grade, 98\%, Aldrich), Pluronic ${ }^{\bullet}$ F-127 (Powder, BioReagent, Sigma), Deionized water (Milli-Q, Millipore), Hydrochloric Acid-HCl (P.A. $37 \%$, Vetec), Rutin hydrate ( $\geq 94 \%$ HPLC, powder, Sigma), Sodium lauryl sulfate-SLS (Vetec); Acetonitrile (UV HPLC spectroscopic, 99.9\%, J.J. Baker); Methanol (UV HPLC 99.9\%, Vetec); Acetic Acid (UV HPLC, spectroscopic 99.9\%, Vetec).

\subsection{Synthesis, Sample Preparation and Analysis}

For the synthesis of mesoporous silica SBA-16, $180 \mathrm{~mL}$ of $\mathrm{HCl}\left(0.4 \mathrm{~mol} \cdot \mathrm{L}^{-1}\right), 1.40$ $\mathrm{g}$ of Pluronic F-127 surfactant and $0.16 \mathrm{~g}$ of the CTAB co-surfactant were diluted in a beaker with $80.0 \mathrm{~mL}$ of deionized water for 20 minutes to form the micelles on a magnetic stirrer (TMA10CF Thelga) [14]. After the complete dissolution of the surfactant, $5.0 \mathrm{~mL}$ of the TEOS silica precursor was added, and kept under vigorous stirring with a mechanical stirrer (713 Fisatom), for 5 minutes. The material was then kept for 5 days at $95.0^{\circ} \mathrm{C}$ in a thermostated ultrasonic bath 


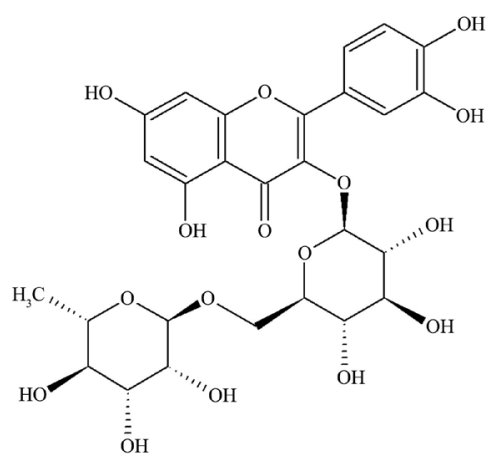

Figure 1. The Rutin structure.

(MA 185 Marconi). Subsequently, the obtained material was washed, filtered and placed in an oven (Fanem 515) at $60.0^{\circ} \mathrm{C}$ for $12 \mathrm{~h}$ to evaporate the water. With regard to the removal of the surfactant and formation of the mesopores, calcination was carried out in a muffle furnace (MA 385/3 Marconi), with a heating rate of $1.0^{\circ} \mathrm{C} \cdot \mathrm{min}^{-1}$ until the temperature reached $500^{\circ} \mathrm{C}$, where the material remained for 3 hours and was subjected to the characterization of Rutin and an impregnation test.

After the synthesis of SBA-16 was completed, optimization tests were carried out to impregnate Rutin on silica. During this procedure, $50.0 \mathrm{mg}$ of silica in 3.0 $\mathrm{mL}$ of the methanolic solution (i.e. methanol/deionized water $1: 1 \mathrm{v} \mathrm{v}^{-1}$ ) of 70.0 mmol. $\mathrm{L}^{-1}$ Rutin $(\mathrm{n}=3)$ was kept under magnetic stirring in a sealed vessel. The methanol was chosen because it is the solvent in which the Rutin has the best solubilization. These samples were kept under stirring for up to $24 \mathrm{~h}$. At the end of every $2 \mathrm{~h}$, the supernatant containing the synthesized material was filtered (using an analytical hydrophilic PTFE syringe filter for $0.45 \mu \mathrm{M}$ ) and oven dried at $60.0^{\circ} \mathrm{C}$ and submitted to the Rutin-SBA-16 characterizations and kinetic release study.

The Rutin quantification in the impregnation and dissolution stages was carried out by High Efficiency Liquid Chromatography-HPLC (Thermo Scientific Finnigan Surveyor) equipped with a Phenomenex Gemini column (NX $5 \mu \mathrm{m}$, C18 $110 \AA, 150 \times 4.6 \mathrm{~mm}$ ) and UV-VIS detection system at a wavelength of 254 $\mathrm{nm}$. The mobile phase consisted of acetonitrile and water acidified with 1.0\% acetic acid. The mobile phase flow was $1.4 \mathrm{~mL}$ per minute. The volume injected was $20.0 \mu \mathrm{L}$ and the retention time of the routine was 3 minutes. The accuracy of the quantification method by HPLC was determined by carrying out addition and recovery tests for 5.00, 15.00 and $30.00 \mu \mathrm{g} \cdot \mathrm{mL}^{-1}$ of Rutin in a solution prepared in $1 \% \mathrm{HCl}$ and $1 \%$ DDS to simulate the $\mathrm{pH}$ of the stomach (i.e. site of interest of the Rutin release activity) and check any possible interference in the readings.

The tests of the impregnated Rutin were run with $50.0 \mathrm{mg}$ of silica $(\mathrm{n}=3)$ in $3.0 \mathrm{~mL}$ of methanol solution of $70 \mathrm{mmol} \cdot \mathrm{L}^{-1}$ Rutin which were performed for a period of 24 hours ( $30 \mathrm{~min}, 1 \mathrm{~h}, 2 \mathrm{~h}, 4 \mathrm{~h}, 6 \mathrm{~h}, 8 \mathrm{~h}, 12 \mathrm{~h}$ and $24 \mathrm{~h}$ ), following centrifugation, $1 \mathrm{~mL}$ of each solution was subjected to HPLC analysis. The assay of 
Rutin liberation was run with $50.0 \mathrm{mg}$ of silica $(\mathrm{n}=3)$ containing the equivalent amount, impregnated with $14.2 \mathrm{mg}$ of Rutin, was dissolved (Logen Scientific Instruments Dissolution Tester) in $390 \mathrm{~mL}$ solution of $1.0 \% \mathrm{HCl}$ and $1.0 \%$ SLS. The solution was kept under stirring at $100 \mathrm{rpm}$ at a temperature of $37.0^{\circ} \mathrm{C}$. At intervals of $2 \mathrm{~h}, 4 \mathrm{~h}, 6 \mathrm{~h}, 8 \mathrm{~h}, 12 \mathrm{~h}, 18 \mathrm{~h}$ and $24 \mathrm{~h}$, aliquots of $5.0 \mathrm{ml}$ were removed and subjected to centrifugation. Subsequently, $1 \mathrm{~mL}$ of each aliquot was subjected to HPLC analysis. The dissolution kinetics was evaluated by the Zero Order, First Order and Higuchi models [18] [19] [20].

\subsection{Physicochemical and Morphological Characterization}

The physicochemical characterizations were performed to confirm the structure of the SBA-16 post-synthesis by scanning electron microscopy-SEM (Jeol JSM-6380 LV), Transmission Electron Microscopy TEM (CM20, Phillips) and X-ray Diffraction-XRD (Bruker D8 Advance).

The SEM characterization was carried out by micrographs obtained by means of the scanning electron microscopy technique, operating at 15 and $30 \mathrm{kV}$. The samples were metallized with gold for 5 minutes, $30 \mathrm{~mA}$ current and $200 \mathrm{mTorr}$ vacuum on a metallizer (Denton Vacuum Desk III).

The TEM was obtained by high voltage, operating up to $200 \mathrm{kV}$, and electron source LaB6 (lanthanum hexaboride). The particles were dispersed in ethanol and sonicated for $1.5 \mathrm{~h}$ in an ultrasonic bath (LimpSonic, LS-3DA-2/X) to obtain the micrographs. The images were captured with a $2 \mathrm{k} \times 2 \mathrm{k}$ CCD camera, using Digital Micrograph software.

The pore geometry and the distance between its centers were obtained by an $\mathrm{X}$-ray diffraction with $\mathrm{CuK} \alpha$ radiation $(\lambda=1.5418 \AA$ ), a Ni filter and a $0.4 \mathrm{~mm}$ slit, operating at $40 \mathrm{kV}$ with a current of $40 \mathrm{~mA}$, and an increment of $0.01^{\circ}$ (in $2 \theta$ ); a goniometer velocity $1^{\circ} \cdot \mathrm{min}^{-1}$ was applied, and sample scanning in the range of $2 \theta$ from $0.7^{\circ}$ to $5^{\circ}$.

Rutin impregnation on silica (Rutin-SBA-16) was confirmed by Fourier-transform infrared spectroscopy-FTIR (FTIR Spectrometer, Bomem MBSeries) and Nitrogen adsorption-desorption isotherms at $77 \mathrm{~K}$ (Micromeritics ${ }^{\circledR}$ ASAP2020 adsorption). The FTIR spectra for calcined SBA-16 and Rutin-SBA-16 were obtained by dispersing the material in $\mathrm{KBr}$ pellets; the spectral range analyzed was 400 to $4000 \mathrm{~cm}^{-1}$.

The Brunauer-Emmett-Teller method-BET [21] [22], was used for specific surface area analysis (SBET) and pore diameter (DP) through $\mathrm{N}_{2}$ adsorptiondesorption experiments at a constant temperature of $77 \mathrm{~K}$. The calcined silica sample was previously degassed at $150^{\circ} \mathrm{C}$ for 20 hours and the sample containing Rutin was degassed at $60.0^{\circ} \mathrm{C}$ for 20 hours.

\section{Results and Discussion}

\subsection{Physicochemical and Morphological Characterization}

Through the micrographs shown in Figure 2, it can be observed that the par- 
ticles have a rhombododecahedra morphology that is consistent with the findings of the literature used for the synthesis of this material [14] [15]. The comments in the micrographs obtained by TEM (Figure 3(a) and Figure 3(b)) are in accordance with this structure (SBA-16). Although it does not show the regular and perfect form of a polyhedron, it is possible that the images are becoming similar to those in the pore system [14] [23] [24].

The X-ray diffraction enabled us to calculate the geometrical pattern of the pores and the distance between their centers. The values of the interplanar distances (dhkl) for all the peaks, were obtained by the Bragg equation [25] [26]. The Miller indices were observed in (110), (200), (211) and (220); these peaks are in the range of $0.90^{\circ}-1.70^{\circ}$, with a peak of greatest intensity in $2 \theta$ around $0.91^{\circ}$ and $\left.\mathrm{a}_{0}=13.7 \mathrm{~nm}\right)\left(\mathrm{a}_{0}=\right.$ unit cell parameter calculated from $\mathrm{d}$-spacings for $\operatorname{Im} \overline{3 \mathrm{~m}}$ ) (Figure 4). The mesoporous silica synthesized presented a porous three-dimensional arrangement of the cubic space group $\operatorname{Im} 3 \mathrm{~m}$, and, then, the body-centered cubic structure of mesoporous silica was confirmed by the XRD analysis [24] [25].

The quantification of impregnated Rutin in the SBA-16 and the evaluation of the dissolution kinetics were carried out by HPLC. The external calibration method was applied to HPLC for the Rutin quantification by using the peak area. The linear range of the calibration curve was $2.5-50.0 \mu \mathrm{g} \cdot \mathrm{mL}^{-1}$, and obtained a linear coefficient $\left(\mathrm{R}^{2}\right)$ of 0.9993 . The limits of detection and quantification were evaluated from the data of the analytical curve of Rutin in $1.0 \% \mathrm{HCl}$ and SLS $1.0 \%$, and obtained values of $0.02 \mu \mathrm{g} \cdot \mathrm{mL}^{-1}$ and $0.07 \mu \mathrm{g} \cdot \mathrm{mL}^{-1}$, respectively. The recoveries obtained were $95.00 \%, 102.50 \%$ and $103.60 \%$ and the accurate rates,
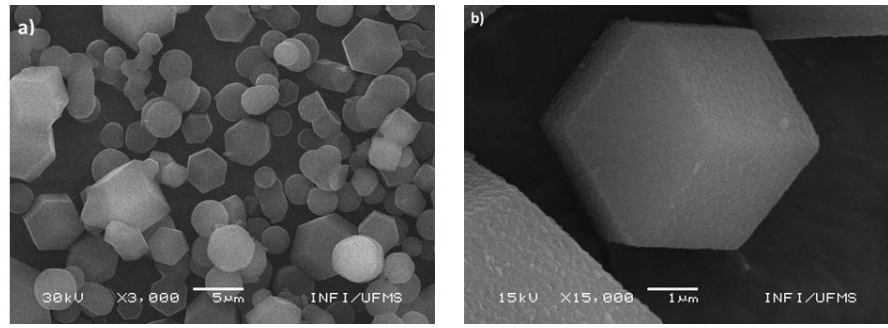

Figure 2. SEM micrographs of silica SBA-16, (a) $3000 \times$ and $30 \mathrm{kV}$; (b) $15,000 \times$ and $15 \mathrm{kV}$.
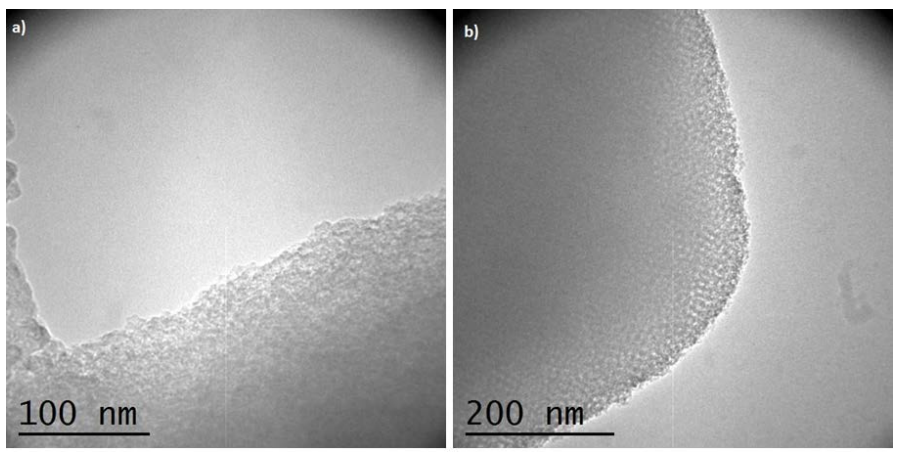

Figure 3. TEM images of SBA-16 sample, (a) $100 \mathrm{~nm}$; (b) $200 \mathrm{~nm}$. 


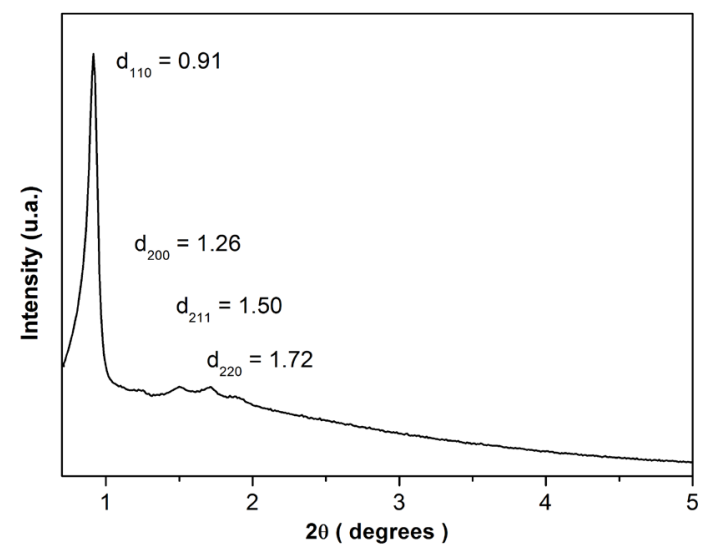

Figure 4. XRD pattern for SBA-16 sample.

represented as relative standard deviation ( $\% \mathrm{RSD}$ ), were $1.06 \%, 0.86 \%$ and $0.20 \%$ for the solutions of $5.00,15.00$ and $3.00 \mu \mathrm{g} \cdot \mathrm{mL}^{-1}$ of Rutin respectively. The amount of impregnated Rutin was quantified by measuring the difference of the initially added Rutin concentration of the supernatant obtained by HPLC. The mechanism through which Rutin interacts with SBA-16 is made possible by the interactions of silanol groups on the surface of silica with the $\mathrm{OH}$ groups of the Rutin molecule [27]. The hydrophilicity of disaccharide of Rutin molecules combined with their hydroxyl groups, enhance the Rutin interaction with $\mathrm{OH}$ surface silica groups through a hydrogen bond and van der Walls interactions, shown in Figure 5 [27] [28] [29]. The best impregnation time, which was 8 hours, was obtained by adsorbing $284 \mu \mathrm{g}$ rutin per mg of silica. The Rutin was released after the impregnation test.

A comparison of the FTIR spectrum of silica impregnated with Rutin with calcined silica is shown in Figure 6. This evaluation includes the vibrational modes of the functional groups of silica and Rutin [30] [31] [32]. The bands in

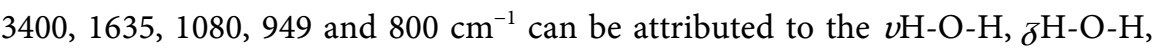

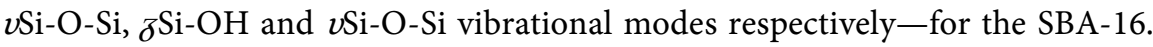
While the presence of the Rutin is confirmed by the bands in 1466 and 1355 $\mathrm{cm}^{-1}$ that can be attributed to $(\zeta \mathrm{C}-\mathrm{H})$, the bands of $2971,2921,2881 \mathrm{~cm}^{-1}$ can be attributed to stretching $(\nu \mathrm{C}-\mathrm{H})$, which indicates an effective impregnation of Rutin on SBA-16.

The characterizations were finalized by conducting tests involving the adsorption-desorption isotherm of $\mathrm{N}_{2}$ to $77 \mathrm{~K}$ to calculate the pore diameter and compare the calcined silica and silica impregnated with Rutin (as in Figure 7(a) and Figure 7(b), respectively). The profile of the isotherms did not change after impregnation, and the structural features of the mesoporous synthesized array were preserved [33]. The comparison of the results of the calcined silica with silica impregnated with Rutin provided the measurements of the specific surface area (SBET), pore diameter (DP) and pore volume (VP), which were $732 \mathrm{~m}^{2} \cdot \mathrm{g}^{-1}, 6.6$ $\mathrm{nm}, 0.55 \mathrm{~cm}^{3} \cdot \mathrm{g}^{-1}$ respectively for Rutin-SBA-16. These data demonstrate that there was a reduction in surface area and pore volume, thus confirming the 
presence of Rutin on silica (i.e. SBET, DP and VP of $806 \mathrm{~m}^{2} \cdot \mathrm{g}^{-1}, 6.6 \mathrm{~nm}, 0.60$ $\left.\mathrm{cm}^{3} \cdot \mathrm{g}^{-1}\right)$ to SBA-16 [14] [24]. The comparison between the DP of SBA-16 and Rutin-SBA-16 shows that the pore diameter did not change; this can be explained by the fact that the Rutin is impregnated inside the pores and not necessarily in the walls of the pore, which would not result in a change in the diameter. This might indicate a non-uniform distribution of Rutin within the silica pores [27].

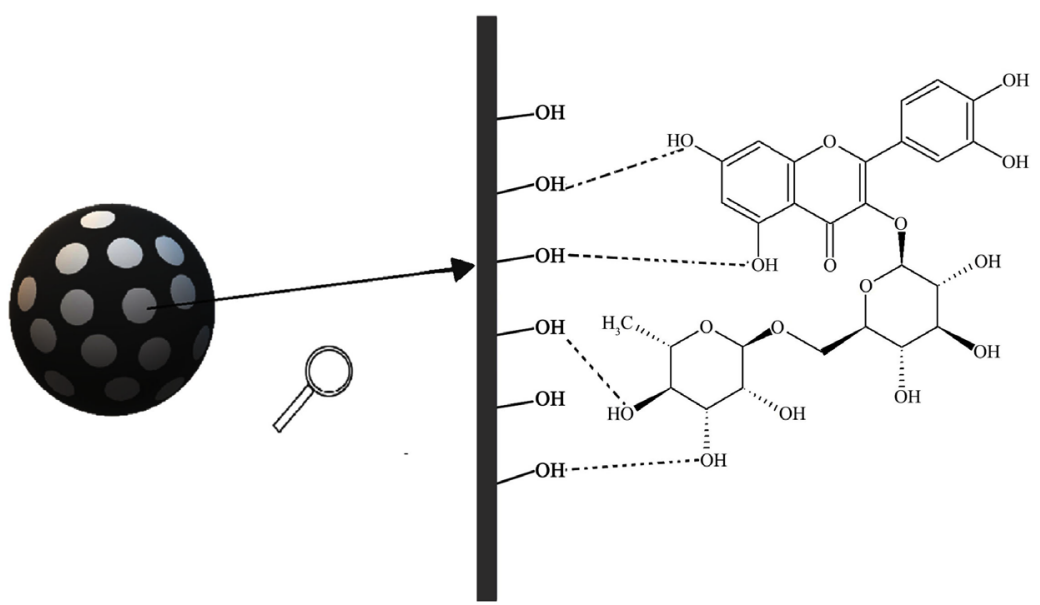

Figure 5. Schematic representation of the interaction of Rutin with the silica surface.

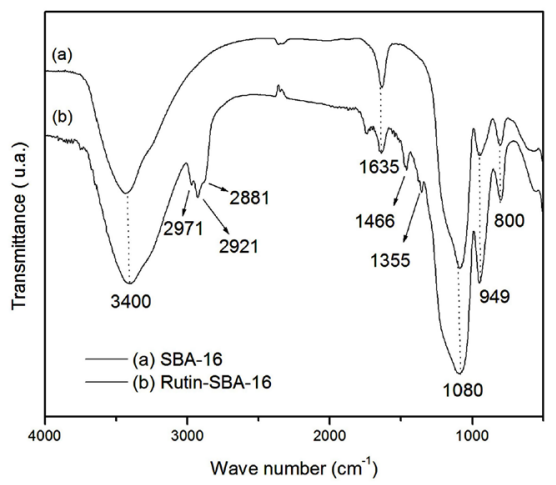

Figure 6. FTIR spectrum of calcined silica and silica impregnated with Rutin.
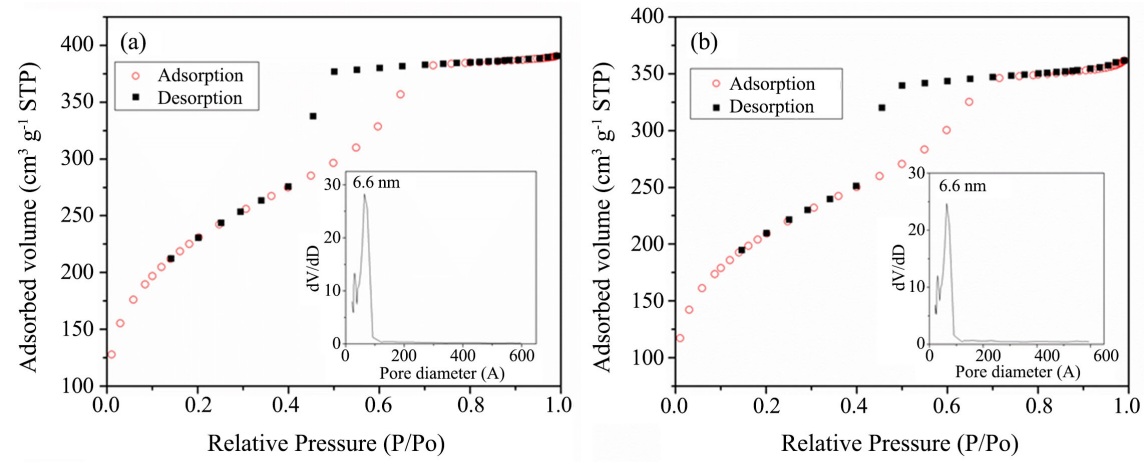

Figure 7. $\mathrm{N}_{2}$ sorption isotherm at $77 \mathrm{~K}$ of SBA-16 material, with pore size distribution (diameter) included, (a) SBA-16 sample; (b) SBA-16 sample-Rutin. 
After the physicochemical characterization of Rutin-SBA-16, there were kinetic studies of controlled release for the models of Zero Order, First Order and Higuchi, as shown in Table 1.

\subsection{Kinetic Release Study of Rutin-SBA-16}

Kinetic studies are widely used to assist in the development of new formulations, assess the influence of changes in the production process and/or in the formulation, monitor quality control from batch to batch of a particular specialist area, and make an evaluation of pharmaceutical equivalence between the presentations of different manufacturers.

The dissolution profile of Rutin that has been evaluated in this work is shown in Figure 8. It is clear from this that the maximum release occurs between 20 $25 \mathrm{~h}$. The release kinetics of the Rutin are called Higuchi (Table 1), and have a high degree of linearity, with a correlation coefficient $\left(\mathrm{R}^{2}\right)$ of 0.999 , as opposed to 0.905 and 0.980 of the zero order and first order models respectively.

In the case of the zero order model, the form of dosage does not fragment (i.e. it maintains its initial area and does not reach a state of equilibrium) by releasing the drug gradually [18] [31] [34]. With regard to the first-order model, the dissolution profiles are already suitable since the pharmaceutical forms contain water-soluble drugs in porous matrices. In this case, the drug is released in proportion to the

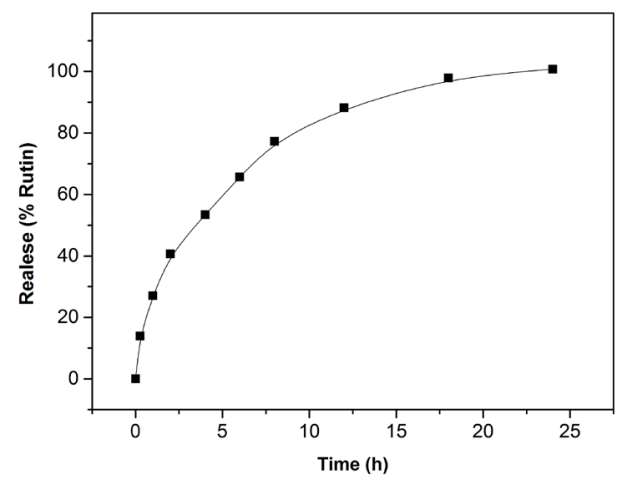

Figure 8. Release profile of Rutin solution.

Table 1. Types of dissolution kinetics models.

\begin{tabular}{|c|c|c|c|c|}
\hline Kinetic Model & Equation & Description & Plot Graph & Ref. \\
\hline Zero order & $C=C_{o}+K_{o} t$ & $\begin{array}{l}\text { Where, } C_{0} \text { is the initial concentration of } \\
\text { drug at time } t=0, K_{0} \text { is zero order rate } \\
\text { constant, } \mathrm{t} \text { is the time taken for } C \\
\text { amount of drug release }\end{array}$ & $\begin{array}{l}\text { Cumulative \% drug release vs. } \\
\text { time }\end{array}$ & $\begin{array}{l}\text { Okano et al., } 1987 \\
\text { Yin et al., } 2009 \\
\text { Park, } 2014\end{array}$ \\
\hline First order & $\log C_{t}=\frac{\left(\log C_{o}-k_{1} t\right)}{2.303}$ & $\begin{array}{l}\text { Where, } C_{t} \text { is amount of drug released in } \\
t \text { time and } C_{0} \text { is the initial amount of } \\
\text { drug, } K_{1} \text { is first order rate constant }\end{array}$ & $\begin{array}{l}\text { Log } \% \text { of drug remaining } v s \text {. time } \\
\text { and the slope of the plot gives the } \\
\text { first order rate constant }\end{array}$ & $\begin{array}{l}\text { Hallam et al., } 1983 \\
\text { Shah and Rajput, } 2017 \\
\text { Mucientes and Peña, } 2009\end{array}$ \\
\hline Higuchi & $Q=K_{H} t^{1 / 2}$ & $\begin{array}{l}K_{H} \text { is Higuchi dissolution constant, } Q \text { is } \\
\text { the amount of drug released in time } t \\
\text { per unit area }\end{array}$ & $\begin{array}{l}\text { Cumulative } \% \text { drug release vs. } \\
\text { square root of time }\end{array}$ & $\begin{array}{l}\text { Gouda et al., } 2017 \\
\text { Higuchi, } 1963 \\
\text { Siepmann and Peppas, } \\
2011\end{array}$ \\
\hline
\end{tabular}


amount that still remains, and at the same time, the released amount decreases over the course of the testing period [19] [34] [35].

The Higuchi release systems are for uncoated devices which are often used to describe the rate of the controlled release of the drug from a matrix system; this is because the yield of the drug is based on Fick's first law of diffusion which is proportional to the square root of time [2] [35] [36]. In this case, the release of the Rutin-SBA-16 occurs by diffusion of the Rutin through the matrix pores by means of the monolithic system, where the interactions that occur between the silica and the Rutin are of the hydrogen bond type [37].

In light of the study material, someone weighing $70 \mathrm{~kg}$ would require the ingestion of approximately $30 \mathrm{mg}$, (i.e. Rutin-SBA-16 containing $120 \mu \mathrm{g} \cdot \mathrm{kg}^{-1} \mathrm{Ru}$ tin) for effective anticancer treatment involving the inhibition of cell proliferation and removal of reactive oxygen species that can cause DNA damage and lead to mutations in a dosage [37]. Although supplementary toxicity tests are needed, the study shows the benefits of Rutin-SBA-16 as a drug delivery system. Since the SBA-16 mesoporous silica of this research represents an interesting carrier matrix for modulating rutin release (Higuchi Model). This ability of silica to modulate release will allow in vivo studies to evaluate different pharmaceutical forms for dose/frequency adequacy of rutin use.

\section{Conclusion}

The techniques of characterization provided proof that the array of mesoporous silica (SBA-16) was prepared successfully. Impregnation of Rutin on silica was confirmed from the FTIR techniques and the adsorption/desorption of nitrogen. The kinetic tests showed high linearity, with a correlation coefficient $\left(\mathrm{R}^{2}\right)$ of 0.999 for the Higuchi model. This was due to the diffusion of Rutin by the pores of the array through the monolithic system, where the interactions that occur between silica and Rutin are of the hydrogen bond type. The Rutin-SBA-16 system released $284 \mu \mathrm{g}$ of Rutin by mg of silica in a period of $24 \mathrm{~h}$. Moreover, it was able to provide a controlled release of the drug and included an array for future tests of toxicities and in vivo applications.

\section{Acknowledgements}

The authors would like to thank the Universidade Federal de Mato Grosso do Sul. This study was financed in part by the Coordenação de Aperfeiçoamento de Pessoal de Nível Superior-Brasil (CAPES) - Finance Code 001. The authors are also grateful to the Conselho Nacional de Desenvolvimento Científico e Tecnológico-Brasil (CNPq) -Finance Code 408054/2013-1 and Fundação de Apoio ao Desenvolvimento do Ensino, Ciência e Tecnologia do Estado de Mato Grosso do Sul-Brasil (FUNDECT-MS) - grants 112/2014, 97/2012 and 06/2011-PRONEM for providing financial support for undertaking this project. The fellowship provided to D.A.G. (Grant 1663746) and J.C.F.K. (Grant 1118148 and 1515004) by CAPES (Coordenação de Aperfeiçoamento de Pessoal de Nível Superior) is also greatly appreciated. 


\section{Conflicts of Interest}

The authors declare no conflicts of interest regarding the publication of this paper.

\section{References}

[1] Koziolek, M., Grimm, M., Schneider, F., Jedamzik, P., Sager, M., Kühn, J.P., Siegmund, W. and Weitschies, W. (2016) Navigating the Human Gastrointestinal Tract for Oral Drug Delivery: Uncharted Waters and New Frontiers. Advanced Drug Delivery Reviews, 101, 75-88. https://doi.org/10.1016/j.addr.2016.03.009

[2] Gouda, R., Baishaya, H. and Qing, Z. (2017) Application of Mathematical Models in Drug Release Kinetics of Carbidopa and Levodopa ER Tablets. Journal of Developing Drugs, 6, 1-8. https://doi.org/10.4172/2329-6631.1000171

[3] Peppas, N.A. (1989) Pharmaceutics: The Science of Dosage Form Design. Journal of Controlled Release, 8, 275-276. https://doi.org/10.1016/0168-3659(89)90050-3

[4] Dolmans, D.E.J.G.J., Fukumura, D. and Jain, R.K. (2003) Photodynamic Therapy for Cancer. Nature Reviews Cancer, 3, 380-387. https://doi.org/10.1038/nrc1071

[5] Chappuis, F., Sundar, S., Hailu, A., Ghalib, H., Rijal, S., Peeling, R.W., Alvar, J. and Boelaert, M. (2007) Visceral Leishmaniasis: What Are the Needs for Diagnosis, Treatment and Control. Nature Reviews Microbiology, 5, 873-882. https://doi.org/10.1038/nrmicro1748

[6] Liu, J., Sonshine, D.A., Shervani, S. and Hurt, R.H. (2010) Controlled Release of Biologically Active Silver from Nanosilver Surfaces. ACS Nano, 4, 6903-6913. https://doi.org/10.1021/nn102272n

[7] Anal, A.K., Bhowmik, D., Gopinath, H., Kumar, B.P., Duraivel, S., Kumar, K.P.S., Borkow, G., Gabbay, J., Zatcoff, R.C., Costa, P., Sousa Lobo, J.M., Higuch, W.I., Sciences, H., Dash, S., Murthy, P.N., Nath, L., Chowdhury, P., Shaikh, H.K., Kshirsagar, R.V., Patil, S.G., Tian, X., Zhang, Z., Wang, S., Diao, Y., Zhao, Z., Lv. D., Ummadi, S., Shravani, B., Rao, N.G.R., Reddy, M.S., Sanjeev, B., Taghizadeh, S.M., Soroushnia, A. and Mohamadnia, F. (2013) Overview on Controlled Release Dosage Forms. International Journal of Pharma Sciences, 3, 258-269. https://doi.org/10.1063/1.5030284

[8] Slowing, I., Viveroescoto, J., Wu, C. and Lin, V. (2008) Mesoporous Silica Nanoparticles as Controlled Release Drug Delivery and Gene Transfection Carriers. Advanced Drug Delivery Reviews, 60, 1278-1288. https://doi.org/10.1016/j.addr.2008.03.012

[9] Kushal, M., Monali, M., Durgavati, M., Mittal, P., Umesh, S. and Pragna. S. (2013) Oral Controlled Release Drug Delivery System: An Overview. International Research Journal of Pharmacy, 4, 70-76. https://doi.org/10.7897/2230-8407.04312

[10] Mendes, L.S., Saska, S., Martines, M.A.U. and Marchetto, R. (2013) Nanostructured Materials Based on Mesoporous Silica and Mesoporous Silica/Apatite as Osteogenic Growth Peptide Carriers. Materials Science \& Engineering C-Materials for Biological Applications, 33, 4427-4434. https://doi.org/10.1016/j.msec.2013.06.040

[11] Ukmar, T. and Planinšek, O. (2010) Ordered Mesoporous Silicates as Matrices for Controlled Release of Drugs. Acta Pharmaceutica, 60, 373-385. https://doi.org/10.2478/v1007-010-0037-4

[12] Renuka, N.K., Praveen, A.K. and Anas, K. (2013) Influence of CTAB Molar Ratio in Tuning the Texture of Rice Husk Silica into MCM 41 and SBA-16. Materials Letter, 109, 70-73. https://doi.org/10.1016/j.matlet.2013.07.074 
[13] Almeida, T.S.D., Guima, K.E., Silveira, R.M., Silva, G.C., Martines, M.A.U. and Martins, C.A. (2017) A Pd Nanocatalyst Supported on Multifaceted Mesoporous Silica with Enhanced Activity and Stability for Glycerol Electrooxidation. RSC Advances, 7, 12006-12016. https://doi.org/10.1039/C6RA28864B

[14] Mesa, M., Sierra, L., Patarin, J. and Guth, J.L. (2005) Morphology and Porosity Characteristics Control of SBA-16 Mesoporous Silica. Effect of the Triblock Surfactant Pluronic F127 Degradation during the Synthesis. Solid State Sciences, 7, 990-997. https://doi.org/10.1016/j.solidstatesciences.2005.04.006

[15] Stevens, W.J.J., Lebeau, K., Mertens, M., Tendeloo, G.V., Cool, P. and Vansant, E.F. (2006) Investigation of the Morphology of the Mesoporous SBA-16 and SBA-15 Materials. The Journal of Physical Chemistry B, 110, 9183-9187. https://doi.org/10.1021/jp0548725

[16] Féres, C.A.O., Madalosso, R.C., Rocha, O.A., Leite, J.P.V., Guimarãesm T.M.D.P., Toledo, V.P.P. and Tagliati, C.A. (2006) Acute and Chronic Toxicological Studies of Dimorphandra mollis in Experimental Animals. Journal of Ethnopharmacology, 108, 450-456. https://doi.org/10.1016/j.jep.2006.06.002

[17] Sharma, S., Ali, A., Ali, J., Sahni, J.K. and Baboota, S. (2013) Rutin: Therapeutic Potential and Recent Advances in Drug Delivery. Expert Opinion on Investigational Drugs, 22, 1063-1079. https://doi.org/10.1517/13543784.2013.805744

[18] Okano, T., Miyajima, M., Komada, F., Imanidis, G., Nishiyama, S., Kim, S.W. and Higuchi, W.I. (1987) Control of Drug Concentration-Time Profiles in Vivo by Zero-Order Transdermal Delivery Systems. Journal of Controlled Release, 6, 99-106. https://doi.org/10.1016/0168-3659(87)90067-8

[19] Hallam, T.G., Clark, C.E. and Jordan, G.S. (1983) Effects of Toxicants on Populations: A Qualitative Approach II. First Order Kinetics. Journal of Mathematical Biology, 18, 25-37. https://doi.org/10.1007/BF00275908

[20] Higuchi, T. (1963) Mechanism of Sustained-Action Medication. Theoretical Analysis of Rate of Release of Solid Drugs Dispersed in Solid Matrices. Journal of Pharmaceutical Sciences, 52, 1145-1149. https://doi.org/10.1002/jps.2600521210

[21] Brunauer, S., Emmett, P.H. and Teller, E. (1938) Adsorption of Gases in Multimolecular Layers. Journal of the American Chemical Society, 60, 309-319. https://doi.org/10.1021/ja01269a023

[22] Lechevallier, S. Jorge, J., Silveira, R.M., Ramond, N.R., Neumeyer, D., Menu, M.J., Gressier, M., Marçal, A.L., Rocha, A.L., Martines, M.A.U., Magdeleine, E., Ghys, J.D. and Verelst, M. (2013) Luminescence Properties of Mesoporous Silica Nanoparticles Encapsulating Different Europium Complexes: Application for Biolabelling. Journal of Nanomaterials, 60, 1-11. https://doi.org/10.1155/2013/918369

[23] Andrade, G.F., Soares, D.C.F., Santos, R.G. and Sousa, E.M.B. (2013) Mesoporous silica SBA-16 Nanoparticles: Synthesis, Physicochemical Characterization, Release Profile, and in Vitro Cytocompatibility Studies. Microporous Mesoporous Materials, 168, 102-110. https://doi.org/10.1007/s10971-017-4557-y

[24] Feliczak-Guzik, A., Jadach, B., Piotrowska, H., Murias, M., Lulek, J. and Nowak, I. (2016) Synthesis and Characterization of SBA-16 Type Mesoporous Materials Containing Amine Groups. Microporous Mesoporous Materials, 220, 231-238. https://doi.org/10.1016/j.micromeso.2015.09.006

[25] Sakamoto, Y., Kaneda, M., Terasaki, O., Zhao, D.Y., Kim, J.M., Stucky, G., Shin, H.J. and Ryoo, R. (2000) Direct Imaging of the Pores and Cages of Three-Dimensional Mesoporous Materials. Nature, 408, 449-453. https://doi.org/10.1038/35044040

[26] Jorgetto, A.O., Pereira, S.P., Silva, R.I.V., Saeki, M.J., Martines, M.A.U., Pedrosa, 
V.A. and Castro, G.R. (2015) Application of Mesoporous SBA-15 Silica Functionalized With 4-Amino-2-Mercaptopyrimidine for the Adsorption of $\mathrm{Cu}(\mathrm{II}), \mathrm{Zn}(\mathrm{II}), \mathrm{Cd}(\mathrm{II})$, $\mathrm{Ni}(\mathrm{II})$, and $\mathrm{Pb}(\mathrm{II})$ From Water. Acta Chimica Slovenica, 62, 111-121. https://doi.org/10.17344/acsi.2014.787

[27] Berlier, G., Gastaldi, L., Sapino, S., Miletto, I., Bottinelli, E., Chirio, D. and Ugazio, E. (2013) MCM-41 as a Useful Vector for Rutin Topical Formulations: Synthesis, Characterization and Testing. International Journal of Pharmaceutics, 457, 177-186. https://doi.org/10.1016/j.ijpharm.2013.09.018

[28] Khan, M.A., Wallace, W.T., Islam, S.Z., Nagpure, S., Strzalka, J., Littleton, J.M., Rankin, S.E. and Knutson, B.L. (2017) Adsorption and Recovery of Polyphenolic Flavonoids Using $\mathrm{TiO}_{2}$-Functionalized Mesoporous Silica Nanoparticles. ACS Applied Materials \& Interfaces, 9, 32114-32125. https://doi.org/10.1021/acsami.7b09510

[29] Berlier, G., Gastaldi, L., Ugazio, E., Miletto, I., Iliade, P., Sapino, S. (2013) Stabilization of Quercetin Flavonoid in MCM-41 Mesoporous Silica: Positive Effect of Surface Functionalization. Journal of Colloid and Interface Science, 393, 109-118. https://doi.org/10.1016/j.jcis.2012.10.073

[30] Martines, M.A.U., Davolos. M.R., Jafelicci Jr., M., Souza, D.F. and Nunes, L.A.O. (2008) $\mathrm{Cr}^{3+}$ and $\mathrm{Cr}^{4+}$ Luminescence in Glass Ceramic Silica. Journal of Luminescence, 128, 1787-1790. https://doi.org/10.1016/j.jlumin.2008.04.011

[31] Yin, W.-X., Wang, X.-Y., Wang, J.-H., Zhuang, H., Sun, K. and Li, L. (2009) FTIR Study of Rutin, Quercetin and Their Metal Complexes. Journal of China University of Mining and Technology, 38, 884-888.

[32] Queiroz, D.F., Dadamos, T.R.L., Machado, S.A.S. and Martines, M.A.U. (2018) Electrochemical Determination of Norepinephrine by Means of Modified Glassy Carbon Electrodes with Carbon Nanotubes and Magnetic Nanoparticles of Cobalt Ferrite. Sensors, 18, 1-12. https://doi.org/10.3390/s18041223

[33] Souza, E.J., Cristante, V.M., Padilha, P.M., Jorge, S.M.A., Martines, M.A.U., Silva, R.I.V., Carmo, D.R. and Castro, G.R. (2011) Attachment of 2,2-Bipyridine onto a Silica Gel for Application as a Sequestering Agent for Copper, Cadmium and Lead Ions from an Aqueous Medium. Polish Journal of Chemical Technology, 13, 28-33. https://doi.org/10.2478/v10026-011-0045-2

[34] Mucientes, A.E. and de la Peña, M.A. (2009) Kinetic Analysis of Parallel-Consecutive First-Order Reactions with a Reversible Step: Concentration-Time Integrals Method. Journal of Chemical Education, 86, 390-392. https://doi.org/10.1021/ed086p390

[35] Shah, P.V. and Rajput, S.J. (2017) A Comparative in Vitro Release Study of Raloxifene Encapsulated Ordered MCM-41 and MCM-48 Nanoparticles: A Dissolution Kinetics Study in Simulated and Biorelevant Media. Journal of Drug Delivery Science and Technology, 41, 31-44. https://doi.org/10.1016/j.jddst.2017.06.015

[36] Siepmann, J. and Peppasm, N.A. (2011) Higuci Equation: Derivation, Applications, Use and Misuse. International Journal of Pharmaceutics, 418, 6-12. https://doi.org/10.1016/j.ijpharm.2011.03.051

[37] Park, K. (2014) Controlled Drug Delivery Systems: Past Forward and Future Back. Journal of Controlled Release, 190, 3-8. https://doi.org/10.1016/j.jconrel.2014.03.054 